\title{
Comparing Mozambican and French People's Conceptualization of Romantic Love $^{*}$
}

\section{Comparando las conceptualizaciones de mozambiques y franceses de amor romántico}

\author{
Germano Vera Cruz ${ }^{\mathrm{a}}$ \\ Eduardo Mondlane University, Mozambique \\ ORCID: http://orcid.org/0000-0002-8297-6933
}

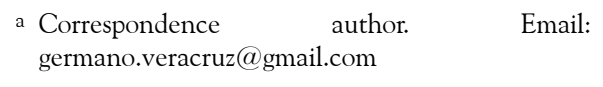

How to cite: Vera Cruz, G. (2019). Comparing Mozambican and French people's conceptualization of romantic love. Universitas Psychologica, 18(1), 1-7. https://doi.org/10.11144/Javeriana.upsy18-1. cmfp

\begin{abstract}
The study compared the way Mozambican and French people conceptualize romantic love. Two subsamples of 238 Mozambican adults and 250 French adults were presented with 27 cards containing vignettes (scenarios) that described the characteristics of someone's relationship regarding degree of passion, the degree of intimacy, and degree of commitment. Participants assessed the intensity of romantic love experienced by the characters in the scenarios using a continuous scale. The way people from both cultures conceptualized romantic love was not entirely similar, but the differences were very subtle. The impact of each component on the judged intensity of love was similar. In both samples, passion and intimacy explained most of the variance. The algebraic structure of the judgment rule was, however, different. Among French participants, the findings were consistent with an equal-weight averaging rule as suggested by previous authors. Among Mozambican participants, the patterns of rating were, however, consistent with a more complex judgment rule. In this rule, the impact of each factor depended on the level of the other factors: A differential weight averaging rule was proposed that can be written Love $=w_{\text {ic }}$ Passion $+w_{\text {pc }}^{\prime}$ Intimacy $+w^{\prime \prime}$ pi Commitment $/ w_{\mathrm{ic}}+w_{\mathrm{pc}}^{\prime}+w^{\prime \prime}$ pi

Keywords

romantic love; conceptualization; algebraic rule; Mozambicans; French.
\end{abstract}

\section{RESUMEN}

El estudio comparó la manera en que los mozambiques y franceses conceptualizan el amor romántico. Dos submuestras de 238 adultos mozambiques y 250 adultos franceses recibieron 27 tarjetas con viñetas (escenarios) que describían las características de la relación de alguien en términos de grado de pasión, grado de intimidad y grado de compromiso. Los participantes evaluaron la intensidad del amor romántico experimentado por los personajes en los escenarios utilizando una escala continua. La forma en que las personas de ambas culturas conceptualizaron el amor romántico no fue completamente similar, pero las diferencias fueron muy sutiles. El impacto de cada componente sobre la intensidad juzgada del amor fue similar. En ambas muestras, la pasión y la intimidad explicaron la mayor parte de la variación. La estructura algebraica de la regla de juicio sin embargo fue diferente. Entre los 
participantes franceses los hallazgos fueron consistentes a lo sugerido por autores anteriores con una regla de igualación de pesos. Sin embargo, entre los participantes de Mozambique, los patrones de calificación fueron consistentes con una regla de juicio más compleja. En esta regla, el impacto de cada factor dependía del nivel de los otros factores: Se propuso una regla de promedio de peso diferencial que se puede escribir Amor $=w$ ic Pasión + $w_{\mathrm{pc}}^{\prime}$ Intimidad $+w_{\mathrm{pi}}^{\prime}$ Compromiso $/ w_{\mathrm{ic}}+w_{\mathrm{pc}}^{\prime}+w_{\mathrm{pi}}^{\prime}$ Palabras clave

amor romantico; conceptualización; reglas algebráicas; mozambiques; franceses.

Sternberg (1986, 1997) has suggested that romantic love involves three separate components: Passion, intimacy, and commitment. According to Falconi and Mullet (2003), intimacy would correspond to the dyadic nature of love as it means togetherness, communication, consideration, caring, supportiveness, and warmth (Fletcher, Simpson, Thomas \& Giles, 1999). Commitment would correspond to the more-than-dyadic, social nature of love as it means social engagement, duration of the relationship, dayto-day living, trust, fidelity, persistence, and responsibility (Fehr, 1999). Finally, passion would correspond to the personal, experienced nature of love as it means excitement, affection, desire, and romance (Regan, 1998).

According to Sternberg, presence or absence of one of these components may define qualitatively different types of love, from no love at all (neither intimacy nor commitment or passion) to consummate love (passion associated with intimacy and commitment). In daily life, however, the combination of these three components is undoubtedly more a matter of degree than an all or none phenomenon. Studies conducted among West-Europeans, CentralAmericans, and Southern Africans have shown that passion was, from people's perspective, the most important component of the love schema, followed by intimacy and then by commitment (Falconi \& Mullet, 2003; Marston, Hecht, Manke, McDaniel \& Reeder, 1998; Morales et al., 2015; Vera Cruz, 2015, 2017). They have also shown that adults with learning disabilities have the same love schema as typical adults, which is unsurprising since love is a fundamental human emotion, which is possibly not only human but common to many primates, at least as an affect such as attachment or connection.

The algebraic structure of the love schema has been examined by Falconi and Mullet (2003). They used the methodological framework of Information Integration theory (Anderson, 2008, 2016). A series of 27 scenarios were created by systematically varying the levels of the three components and participants of various ages were asked to associate a degree of true romantic love to each combination of passion, intimacy, and commitment. One sample of scenarios used in this study was the following: 'Between Ines and Victor, it is full passion. They, however, do not experience a very intimate relationship; for example, they hesitate to talk about everything openly. Also, they live in separate places. They sometimes evoke matrimonial plans, but there is currently nothing concrete about these plans. To what extent do you think that Ines and Victor truly love each other?'

Factorial plots of mean responses in terms of degree of true love showed a nice pattern of parallelism, which indicated that the algebraic structure of the romantic love schema was of an additive type (Anderson, 1982). Subsequent work showed that the exact algebraic rule was of an equal-weight averaging type. The rule suggested by Falconi and Mullet (2003) was:

Love $=w$ Passion $+w^{\prime}$ Intimacy $+w$ " Commitment $/ w+w^{\prime}+w^{\prime \prime}$. These findings have been corroborated using a between-subject design (Mullet \& Chasseigne, 2018).

One direct implication of these findings was that, as the love schema is conceptualized as an averaging, compensatory schema, where a decrease in one factor (e.g., intimacy) may be compensated for by an increase in another factor (e.g., commitment). If two lovers are forced to live separately for some time due to change in working conditions, some increment in commitment (e.g., getting married) can be viewed by each partner and by close others as a way to reestablish the original balance. In other words, knowing the structure of the love schema 
is not just a laboratory nicety; it has unexpected daily life consequences on the way people can manage their most fundamental relationships.

As, until now, the structure of the romantic love schema has been examined in only a few countries, the present study was aimed at examining it in a culturally very different country than France: Mozambique. The same set of 27 scenarios used in the study by Falconi and Mullet (2003) was applied to a sample of adults living in Mozambique and, for the sake of direct comparison, to a sample of adults of the same ages and gender living in France. Our hypothesis was that, given the fact that love is a fundamental emotion the structure of the love schema would be similar in both samples.

\section{Method}

\section{Participants}

The first subsample was composed of 238 Mozambican adults aged 18-61 ( $M=29.7$; SD $=14.7 ; 123$ men and 127 women). Thirteen percent of participants were single, $27 \%$ of the participants lived with their love partner, and $31 \%$ of the participants were married. Twenty-two percent of participants had a low educational level (did not complete high school), $52 \%$ of participants had a moderate educational level (had completed high school), and 17\% of participants had a high educational level (university degrees). The second subsample was composed of 250 French adults aged 18-64 $(M=27.6 ; S D=11.4 ; 115$ men and 135 women). Fifty-eight percent of participants were single, $26 \%$ of the participants lived with their love partner, and $16 \%$ of the participants were married. Eleven percent of participants had a low educational level, $43 \%$ of participants had a moderate educational level, and $45 \%$ of participants had a high educational level.

All participants were unpaid volunteers recruited and tested by the author. They were contacted while walking along the streets of Maputo (Mozambique) and Poitiers and Toulouse (France). I have explained the purpose of the study and they were asked to participate. Once informed consent was obtained, they were invited to the local university for testing. The diversity of the population in Poitiers, Toulouse and Maputo city enabled the recruitment of participants with various demographic characteristics.

\section{Material}

The material consisted of 27 cards containing vignettes (scenarios) composed of all combinations of the three love constructs: Passion, intimacy, and commitment. Each of the 27 vignettes described the characteristics of a love relationship in terms of the degree of passion (low, intermediate and high), the degree of intimacy (low, intermediate and high), and the degree of commitment (low, intermediate and high). The design was a three within-subject factor design: Passion $\mathrm{x}$ Intimacy $\mathrm{x}$ Commitment, $3 \times 3 \times 3$. The question was: In your opinion, what is the intensity of love involved in this relationship? The response scale was an 11-point scale ranging from Not at all in love (0) to Fully in love (10). A series of pilot studies were realized in Mozambique and France to check whether each scenario was, from people's views, fully realistic.

\section{Procedure}

Each participant was tested individually. The procedure had two phases. In the familiarization phase, participants were explained what was expected of them. For each scenario, they had to assess the intensity of love involved. Each participant was then presented with 13 of the 27 scenarios, in a random order, and they provided the first set of ratings. After completing their ratings, they could compare them and make changes until they were satisfied with the entire set of ratings. In the experimental phase, participants were presented with the whole set of 27 scenarios. They provided ratings at their own pace. They were neither allowed to compare responses nor go back and make changes except in cases of evident mistake. 
As stated early, testing took place in a room at the University of Poitiers, at the University of Toulouse (France), and the Eduardo Mondlane University (Mozambique). In some cases, however, testing took place at the participant's house. The study conformed to current laws in the two countries in which it took place; that is, free and informed consent was obtained from each participant, and strict anonymity was secured. The research was approved by the Board of Trustees of the University Eduardo Mondlane (Mozambique).

\section{Results}

\section{Figure 1}

Judged Level of Love ( $y$-axis) as a Function of Passion (curves), Intimacy ( $x$-axis) and Commitment (panels), among Mozambicans (top panels) and French (bottom panels)
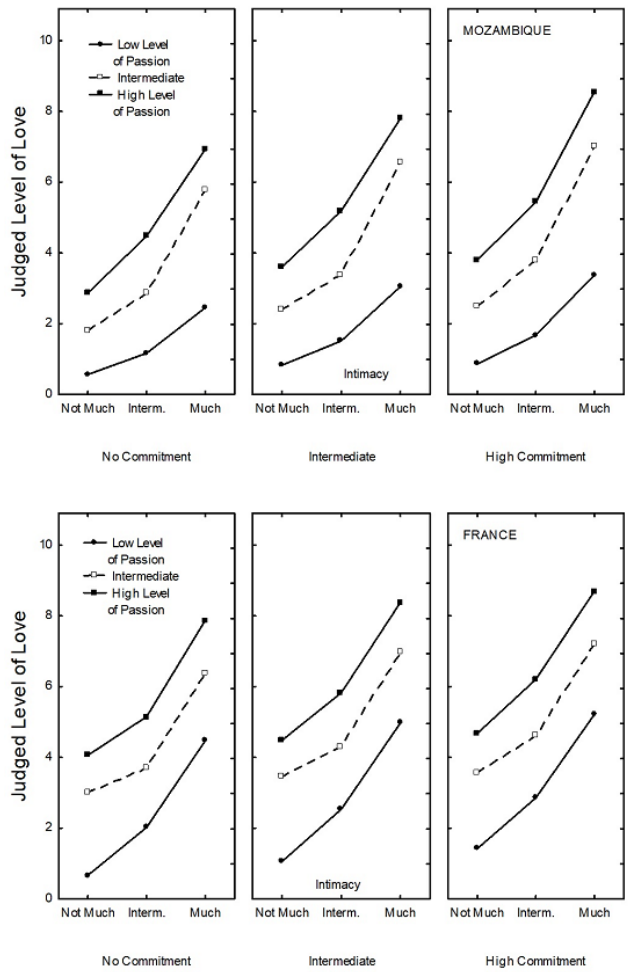

Each rating made by each participant was converted into a numerical value expressing the distance between the point on the response scale and the left anchor serving as an origin. These numerical values were then subjected to graphical and statistical analyses. Before statistical processing, however, each individual pattern of ratings was analyzed visually. Seventeen participants whose ratings were either seemingly aleatory or not differentiated at all were deleted from both subsamples.

An overall ANOVA was conducted on ratings from the remaining 471 participants. Its design was Country $\mathrm{x}$ Passion $\mathrm{x}$ Intimacy x Commitment, $2 \times 3 \times 3 \times 3$. Results are shown in Annex A, and Figure 1. Owing to the great number of comparisons (15), the significance threshold was set at 0.003 (Bonferroni correction). Unsurprisingly, ratings were higher when the level of passion was high $(M=6.78)$, the level of intimacy was high $(\mathrm{M}=7.20)$, and the level of commitment was high $(M=5.53)$ than when the levels of these factors were low $(\mathrm{M}=3.26,3.53$, and 4.68, respectively). Ratings were lower among Mozambican participants $(M=4.71)$ than among French participants $(M=5.58)$.

The two-way interactions involving the Country factor were not significant. Several of the other two-ways interactions were, however, significant, and concentrated in their bilinear component. Also, all three-way interactions involving the Country factor were significant and concentrated in their trilinear component. As a result, two separate ANOVAs were conducted, one for each country.

The first additional ANOVA was conducted on ratings from the remaining 238 Mozambican participants. Its design was Passion x Intimacy x Commitment, $3 \times 3 \times 3$. Results are also shown in Table 1 . Ratings were higher when the level of passion was high $(M=6.41)$, the level of intimacy was high $(M=6.73)$, and the level of commitment was high $(M=5.12)$ than when the levels of these factors were low $(M=$ 2.72, 3.14, and 5.21, respectively). All two-way interactions were significant and concentrated in their bilinear component. For example, the effect of passion was stronger when the level of intimacy was high $(8.76-3.96=4.80)$ than when it was low $(4.42-1.75=2.67)$. The three-way interaction was, however, not significant. 
The second additional ANOVA was conducted on ratings from the remaining 233 French participants, with a similar design. Ratings were higher when the level of passion was high $(M=7.15)$, the level of intimacy was high $(M=7.68)$, and the level of commitment was high $(M=5.94)$ than when the levels of these factors were low $(M=3.80,3.93$, and 5.15 , respectively). By contrast with what was observed in the preceding analysis, although two of the two-way interactions were significant, these interactions were not concentrated in their bilinear component. For example, the effect of passion was similar whether the level of intimacy was high $(9.32-5.89=3.43)$ or low $(5.41-$ $2.05=3.36)$. The three-way interaction was not significant.

\section{Discussion}

Contrary to our hypothesis, the structure of the love schema was not completely similar among Mozambican and French people. The differences between the way love is conceptualized in both cultures were, however, very subtle. The impact of each component was similar. In both samples, passion explained about $46 \%$ of the variance, intimacy about $51 \%$ and commitment only $3 \%$. Variations from one subsample to the other were observed, but they were not significant. The algebraic structure of the rule was, however, different. Among French participants, the patterns of ratings were roughly parallel, and findings were, as a result, consistent with the equal-weight averaging rule suggested by Falconi and Mullet (2003). Among Mozambican participants, the patterns of rating were fanshaped to the right; that is, findings were not consistent with this rule. The impact of each component depended on the level of the other components: A differential weight averaging rule can account for such variations in impact. This rule can be written

Love $=w_{\text {ic }}$ Passion $+w_{\mathrm{pc}}^{\prime}$ Intimacy $+w_{\mathrm{pi}}^{\prime \prime}$ Commitment $/ w_{\mathrm{ic}}+w_{\mathrm{pc}}^{\prime}+w_{\mathrm{pi}}^{\prime \prime}$

where $w$ ic is the weight of the passion factor, which depends on intimacy and commitments levels, $w_{\mathrm{pc}}$ is the weight of the intimacy factor, which depends on passion and commitments levels, $w_{\text {pi }}$ is the weight of the commitment factor, which depends on passion and intimacy levels.

This rule is more complex and, in some way, more demanding than the rule found among French participants. Among Mozambican participants, the importance attributed to passion increases as a function of the level of intimacy. Passion is attributed more impact when the subject of this emotion (the partner) is well-known (full intimacy) than when it is not very well known (no intimacy). In the same vein, passion is attributed more impact when the subject of this emotion is a long-time one (e.g., married partner) than when it is a temporary encounter (no commitment). These variations are highly meaningful. They may explain why between Mozambican and French participants the difference in overall rating is of about a onepoint size on an 11-point scale. Mozambicans are more demanding at the time of judging the deepness of love between two persons than French because their romantic love schema is subtler.

\section{Limitations}

This study has, of course, limitations. First, the two groups of participants were convenience samples and were of only moderate size: Generalizations must be made with caution. Second, the participants responded to vignettes, not to real situations. In cross-cultural studies, the use of vignettes, however, is, beneficial - it allows to conduct statistical analyses to reveal how people weigh and combine separate pieces of information independently of other contextual factors and this has been validated (e.g., Fruchart, Rulence-Pâques, \& Mullet, 2007). Third, the design was a within-subject design, and demand and order effects could be present. Mullet and Chasseigne (2018) have, however, shown that concerns about the use of such designs for studying human judgment are exaggerated. Fourth, the time and effort 
needed to respond to multiple scenarios may have resulted in the loss of concentration for some participants. Finally, our 3 × 3 × 3 design did not allow for estimating weights independently of scale values, which enables direct comparison with Falconi and Mullet's (2003) difficult. Separately assessing weights and scale values using the AVERAGE program (Zalinski \& Anderson, 1991) would have required doubling the number of scenarios since three additional $3 \times 3$ designs would have been necessary, which was not compatible with our concerns about participants' level of fatigue at the end of the procedure.

\section{Directions for Future Studies}

Future studies should focus on diversifying the participants' cultures, avoiding focusing only on Western Europeans or Southern Africans. Do Hinduists, Buddhists or Muslims, for example, have qualitatively different conceptualizations of romantic love? Information Integration Theory is particularly well suited for such intercultural studies (Mullet et al., 2016). Future studies should also use a more varied set of partnerships. Do people conceptualize romantic love between females (lesbian partners) or between males (gay partners) in the same way as they conceptualize love in the heterosexual situation? Finally, future studies should examine whether the complex typology of love suggested by Sternberg (1997), which, for example, includes (a) liking (intimacy only), (b) infatuated love or "limerence" (passion only), and (c) companionate love or compassionate love (intimacy and commitment) is empirically grounded and possess cross-cultural generality.

\section{References}

Anderson, N. H. (2008). Unified social cognition. New York, NY: Psychology Press.

Anderson, N. H. (1982). Methods for information integration theory. New York, NY: Academic Press.
Anderson, N. H. (2016). Information integration theory: Unified psychology based on three mathematical laws. Universitas Psychologica, 15(3), 1-7. https://doi.org/10.11144/Javeria na.upsy15-3.iitu

Falconi, A., \& Mullet, E. (2003). Cognitive algebra of love through the adult live. International Journal of Aging and Human Development, 57(3), 275-290. https://doi.or g/10.2190/NPQH-MDLX-F48U-AA35

Fletcher, G. J. O., Simpson, J. A., Thomas, G., \& Giles, L. (1999). Ideals of intimate relationships. Journal of Personality and Social Psychology, 76(1), 72-89. http://dx.do i.org/10.1037/0022-3514.76.1.72

Fehr, B. (1999). Lay people's conceptions of commitment. Journal of Personality and Social Psychology, 76(1), 90-103. http://dx.d oi.org/10.1037/0022-3514.76.1.90

Fruchart, E., Rulence-Pâques, P., \& Mullet, E. (2007). Ecological validity test of laboratory studies on information integration. Teorie E) Modelli, 12(1-2), 281-288. Retrieved from https://www.researchgate.net/publica tion/258105275_Ecological_validity_test of_laboratory_studies_on_information_int egration

Marston, P. J., Hecht, M. L., Manke, M. L., McDaniel, S., \& Reeder, H. (1998). The subjective experience of intimacy, passion, and commitment in heterosexual loving relationships. Personal Relationships, 5(1), 15-30. http://dx.doi.org/10.1111/j.1475-68 11.1998.tb00157.x

Morales, G. E., Lopez, E. O., Castro, C., Charles, D. J., Mezquita, Y. N., \& Mullet, E. (2015). Conceptualization of romantic love among adults with Down's syndrome. Sexuality and Disability, 33(3), 339-348. http://dx.doi.org /10.1007/s11195-014-9368-2

Mullet, E., \& Chasseigne, G. (2018). Assessing information integration processes: A comparison of findings obtained with between-subjects designs versus withinsubjects designs. Quality $\mathcal{E}$ Quantity, 52 (4), 1977-1988. http://dx.doi.org/10.1007/s111 35-017-0592-6 
Mullet, E., López López, W., Kpanake, L., Mukashema, I., Armange, R., Kamble, S.,... Neto, F. (2016). Functional measurement in the field of ethics in politics. Universitas Psychologica, 15(3). http://dx.doi.org/10.11144/Javerian a.upsy15-3.fmf

Regan, P. C. (1998). Of lust and love: Beliefs about the role of sexual desire in romantic relationships. Personal Relationships, 5(2), 139-157. http://dx.doi.org/10.1111/j.14756811.1998.tb00164.x

Sternberg, R. J. (1986). A triangular theory of love. Psychological Review, 93(2), 119-135. http://dx.doi.org/10.1037/0033-2 95X.93.2.119

Sternberg, R. J. (1997). Construct validation of a triangular love scale. European Journal of Social Psychology, 27(3), 313-335. http://dx.doi.org/10.1002/ (SICI) 1099-0992(199705)27:3<313::AID EJSP824>3.0.CO;2-4

Vera Cruz, G. (2015). Sexuality, love and physical attractiveness: Euro-Western vs. Southern Africa perspectives. Berlin, Germany: LAP Lambert Academic Publishing.

Vera Cruz, G. (2017). Love in crosscultural perspective: Mozambique-France comparison. Journal of Psychology in Africa, 27(4), 334-337. https://doi.org/10.1080/14 330237.2017 .1347754

Zalinski, J., \& Anderson, N. H. (1991). Parameter estimation for averaging theory. In N. H. Anderson (Ed.), Contributions to Information Integration Theory (Vol. 1, pp. 353-394). Hillsdale, NJ: Erlbaum.

\section{Appendix A}

Results of the Overall ANOVA and of the Two Separate ANOVAs (Mozambique and France)

\begin{tabular}{|c|c|c|c|c|c|c|}
\hline \multirow{2}{*}{\multicolumn{2}{|c|}{ Overall }} & d] & $M S$ & $F$ & $p$ & $\mathrm{Eta}^{2}$ \\
\hline & & & & & & \\
\hline & & 2410.62 & 91.88 & 0.001 & 0.16 \\
\hline \multicolumn{2}{|l|}{ Passion (P) } & & 13326.83 & 1525.11 & 0.001 & 0.76 \\
\hline \multicolumn{2}{|c|}{ Intimacy (I) } & & 14892.69 & 2965.14 & 0.001 & 0.86 \\
\hline \multicolumn{2}{|c|}{ Commitment $(\mathrm{C})$} & & 91.41 & 552.37 & 0.001 & \\
\hline \multicolumn{2}{|l|}{$\mathrm{S} \times \mathrm{P}$} & & 35.52 & 4.06 & 0.02 & 0.01 \\
\hline \multicolumn{2}{|l|}{$\mathrm{S} \times \mathrm{I}$} & & & & 26 & 0.00 \\
\hline \multirow{2}{*}{\multicolumn{2}{|c|}{$\begin{array}{l}\text { SxC } \\
\text { PxI }\end{array}$}} & & & & 0.06 & 0.01 \\
\hline & & & 145.52 & 58.75 & 0.001 & 0.11 \\
\hline \multirow{3}{*}{$\mathrm{PxC}$} & Bilinear & & 427,52 & 101,16 & 0.001 & \\
\hline & & 4 & & 19.58 & 0.001 & 0.0 \\
\hline & Bilinear & 1 & & & 0.001 & \\
\hline \multirow[t]{2}{*}{$\mathrm{IxC}$} & & 4 & & 23.15 & 001 & 0.0 \\
\hline & Bilinear & & 553 & 57.63 & 0.001 & \\
\hline \multirow[t]{2}{*}{$\mathrm{xPxI}$} & & & & & & 0.1 \\
\hline & Trilinear & 1 & & & & \\
\hline \multirow[t]{2}{*}{$\mathrm{S} \times \mathrm{IxC}$} & & 4 & & 15.53 & 0.001 & 0.03 \\
\hline & Trilinear & 1 & & 20.92 & 0.001 & \\
\hline \multirow[t]{2}{*}{$\mathrm{S} \times \mathrm{P} \times \mathrm{C}$} & & 4 & & & 0.001 & 0.03 \\
\hline & Trilinear & 1 & & & & \\
\hline \multirow[t]{2}{*}{$x \mathrm{IxC}$} & & 8 & & & 04 & 0.0 \\
\hline & Trilinear & 1 & & .66 & 0.20 & \\
\hline \multicolumn{2}{|c|}{$\mathrm{S} \times \mathrm{PXIxC}$} & 8 & & & 0.04 & 0.0 \\
\hline \multirow{2}{*}{\multicolumn{2}{|c|}{$\begin{array}{l}\text { Quadrilin } \\
\text { Mozambique }\end{array}$}} & 1 & & & 0.54 & \\
\hline & & & & & & \\
\hline \multicolumn{2}{|c|}{ Passion $(\mathrm{P})$} & & 7421.02 & 892.64 & 0.001 & 0.79 \\
\hline \multicolumn{2}{|l|}{ Intimacy (I) } & & 7209 & 1286.60 & 0.001 & 0.84 \\
\hline \multicolumn{2}{|c|}{ Commitment (C) } & & & 9.08 & 0.001 & 0.57 \\
\hline \multirow[t]{2}{*}{$P \times I$} & & & & 03.62 & 0.001 & 0.30 \\
\hline & Bilinear & & & 4 & 0.001 & \\
\hline \multirow[t]{3}{*}{$\mathrm{PxC}$} & & 4 & 16.67 & 27.37 & 0.001 & 0.10 \\
\hline & Bilinear & 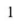 & & & & \\
\hline & & 4 & & & 001 & 0.1 \\
\hline & Biline: & & & & 001 & \\
\hline Are & & & & & & 0.0 \\
\hline & Trilinear & 1 & & 0.19 & 0.66 & \\
\hline & & & & & & \\
\hline issio & & & & 649.45 & & \\
\hline ti & & & & & & \\
\hline Comm & nt (C) & & & 96 & & \\
\hline I & & & & & 0.001 & 0.03 \\
\hline & Bilinea & & & & 0.64 & \\
\hline & & & & & 0.24 & 0.01 \\
\hline & & & & & & \\
\hline$C$ & & & & & & 0.03 \\
\hline & & & & & 0.03 & \\
\hline & & & & & 0.11 & 0.01 \\
\hline & Trilinear & 1 & 1.33 & 1.80 & 0.18 & \\
\hline
\end{tabular}

\section{Notes}

* Research article 